\title{
Intermolecular Carboamination Catalyzed by Palladium
}

Category

Metal-Catalyzed

Asymmetric

Synthesis and

Stereoselective

Reactions

\section{Key words}

palladium catalysis

furoindolines

carboamination

intermolecular reaction

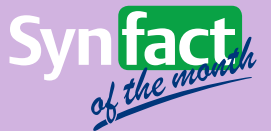

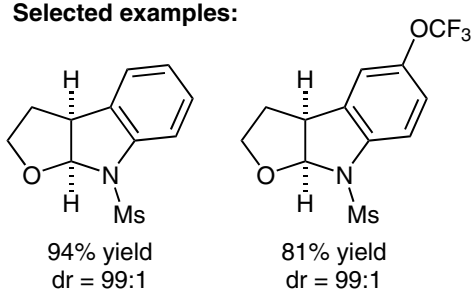

$\mathrm{dr}=99: 1$<smiles>[NH3+][N+](=O)Nc1ccccc1Br</smiles>

$R^{1}$

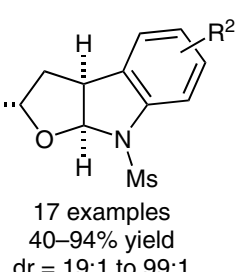
$\mathrm{dr}=19 \cdot 1$ to $99: 1$

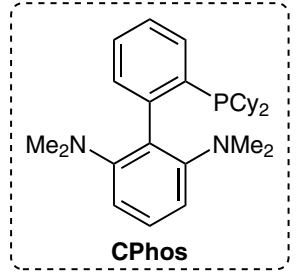

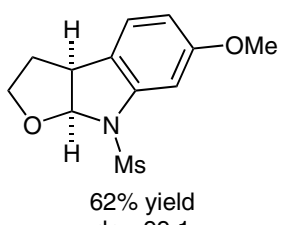

$\mathrm{dr}=99: 1$<smiles>[Y6]N1c2ccccc2[C@@H]2C[C@@H](c3ccc(OC)cc3)O[C@H]21</smiles>
$\mathrm{dr}=25: 1$

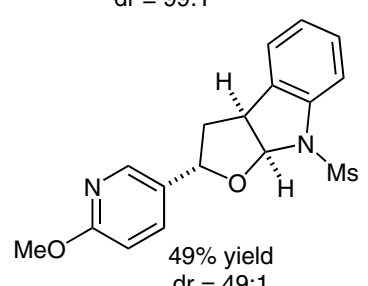

$\mathrm{dr}=49: 1$<smiles>[Y5]N1c2cc(N)ccc2[C@H]2CCO[C@@H]21</smiles>

$40 \%$ yield $\mathrm{dr}=99: 1$

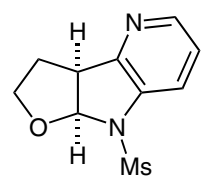

$75 \%$ yield $\mathrm{dr}=99: 1$

\section{Selected examples of the enantioselective carboamination (preliminary):}

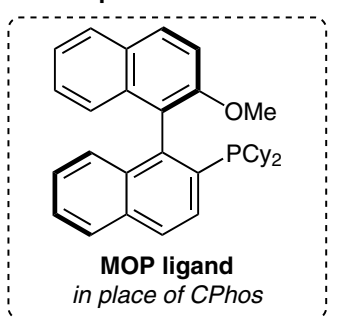

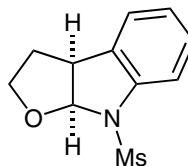

$69 \%$ yield

$\mathrm{dr}=99: 1$

$73 \%$ ee<smiles>COc1ccc2c(c1)[C@H]1CCO[C@@H]1N2S(C)(=O)=O</smiles>

\section{$20 \%$ yield}

$\mathrm{dr}=99: 1$

$72 \%$ ee

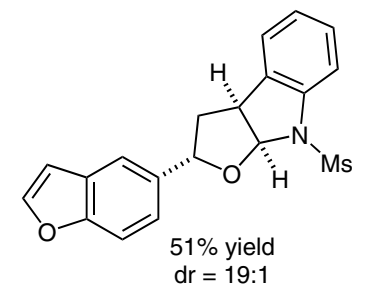

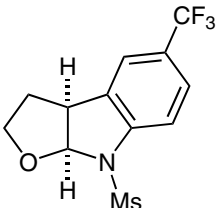

$49 \%$ yield

dr $=99: 1$

$69 \%$ ee
Significance: As part of the family of indole alkaloids, furoindoline structures represent a recurrent motif in many biologically active compounds and pharmaceuticals. The authors capitalized on their previous palladium-catalyzed stereoselective intermolecular carboetherification of dihydrofuranes for the development of a novel palladium-catalyzed syn-carboamination. In addition to the high levels of diastereoselectivity obtained, the authors present preliminary results toward the development of an enantioselective version of the reaction.
Comment: After careful optimization of the reaction conditions, mesyl-protected 2-bromo anilines were reacted with an excess of dihydrofuran and dihydrofuran derivatives in the presence of $\left[\mathrm{Pd}_{2}(\mathrm{dba})_{3}\right]$ and CPhos to afford the corresponding furoindoline products in moderate to good yields and good to excellent diastereoselectivities. Preliminary studies toward the development of an enantioselective version of the reaction are exemplified by the six examples reported (20-70\% yield, 63-73\% ee).

SYNFACTS Contributors: Mark Lautens, Ivan Franzoni 